\title{
Interphase cytogenetics using biotin and digoxigenin labelled probes II: simultaneous differential detection of human and papilloma virus nucleic acids in individual nuclei
}

\author{
C S HERRINGTON, J BURNS, A K GRAHAM, B BHATT, J O'D McGEE \\ From the University of Oxford, Nuffield Department of Pathology and Bacteriology, John Radcliffe Hospital, \\ Oxford
}

SUMMARY A method was developed for the simultaneous detection of viral and human DNA in contrasting colours in routine formalin fixed, paraffin wax embedded biopsy specimens. This was achieved by non-isotopic in situ hybridisation (NISH) with a biotinylated Y chromosome probe and digoxigenin labelled probe for human papilloma virus type 6 (HPV 6). The tissues studied were peripheral lymphocytes, tonsil, and penile warts. The hybridisation signals produced by biotinylated probes were visualised in red using streptavidin peroxidase and those produced by digoxigenin labelled probes as a blue/black colour using anti-digoxigenin alkaline phosphatase. In lymphocytes and tonsil $95-100 \%$ of cells had a detectable Y chromosome; in warts only $60-70 \%$ of infected keratinocytes near the skin surface had a demonstrable $Y$ chromosome. This suggests that this chromosome is lost or occluded in cell maturation. In simultaneous double hybridisation with both probes, HPV and Y sequences were demonstrable within the same nucleus in penile warts.

This technique permits the simultaneous differential detection of two nuclei acid sequences in interphase nuclei and will have application in analysis of putative dual HPV infections and in determining the intranuclear spatial relations between nucleic acids in interphase nuclei.

The detection of two antigens, or nucleic acid and antigen, within the same cell type or tissue has been achieved by either double immunohistochemistry or combining non-isotopic in situ hybridisation (NISH) and immunohistochemistry, respectively. This has been approached by sequential detection of antigens using different coloured substrates for the same detector enzyme. ${ }^{1}$ Alternatively, antigens and nucleic acids have been visualised by two different detector enzymes. ${ }^{2}$ A logical extension of this is to apply the detection systems to simultaneous NISH of two nucleic acids. To avoid sequential hybridisation it is necessary to use more than one reporter molecule to label DNA. Acetaminofluorene (AAF) and mercury labelled probes have been used to detect different chromosome specific probes. These labels have been visualised primarily with fluorescence detection systems to analyse chromosomes in isolated cultured or tumour derived cells. ${ }^{3-6}$ The application of these systems to formalin fixed, paraffin wax embedded material is unsatisfactory because of tissue autofluorescence. Therefore, alternative DNA reporters using two different non-fluorescence detection systems have been used; digoxigenin labelled probes detected using alkaline phosphatase have been shown to be as sensitive as biotin labelled probes detected using peroxidases ${ }^{7}$ for the detection of HPV 16 in CaSki cells fixed in paraformaldehyde. This report shows that this system can be used for simultaneous detection of viral and mammalian nucleic acids in two colours within the same nucleus in material fixed in aldehyde and embedded in paraffin wax.

\section{Material and methods}

All chemicals were purchased from Sigma (UK) unless otherwise stated.

The probes studied were pHY2 $1,{ }^{8}$ a $2 \cdot 1$ kilobase pair Y chromosome specific repeat sequence cloned into pBR328 and HPV6b, which consists of the amp2 fragment cloned into pBR322. ${ }^{9}$ The labelling of probes was achieved by nick translation using both biotin and digoxigenin as described in the previous report. ${ }^{7}$ 
LYMPHOCYTE PREPARATION

Whole blood in ethylenediaminetetra-acetic acid was added to an equal volume of phosphate buffered saline (PBS) (0.15 mol/1 sodium chloride, $0.01 \mathrm{~mol} / 1$ phosphate buffer, $\mathrm{pH} \mathrm{7.4)}$ in sterile tubes and $4 \mathrm{ml}$ of the mixture layered over $3 \mathrm{ml}$ of Ficoll-Paque (Pharmacia, UK). The mixture was spun at $600 \mathrm{~g}$ for 20 minutes and the cells at the buffer/Ficoll-Paque interface collected and washed twice in PBS. The cells were resuspended in $75 \mathrm{mmol} / 1$ potassium chloride and incubated at $37^{\circ} \mathrm{C}$ for 15 minutes, washed in PBS, and fixed in methanol:acetic acid 3:1 (v/v) for 10 minutes. Spreads were made by dropping $5 \mu$ l aliquots of cells, resuspended in fresh methanol:acetic acid $(3: 1=v / v)$, on to pre-cleaned, three-spot multiwell slides (Hendley, Essex) and air dried.

\section{PARAFFIN WAX SECTIONS}

These were prepared by modifying slightly the method of Burns et al..$^{10}$ In essence four-spot multiwell slides (Hendley; Essex) were coated with $2 \%$ aminopropylethoxysilane after cleaning in $2 \%$ Decon 90 (Scientific Supplies Co, UK) and air dried after washing in distilled water. Sections were attached and baked either overnight at $60^{\circ} \mathrm{C}$ or for 45 minutes at $75^{\circ} \mathrm{C}$ if required immediately. After heating to $75^{\circ} \mathrm{C}$ for 15 minutes they were plunged into xylene while still hot. The xylene was changed once (10 minutes each wash) and slides were washed in $99 \%$ ethanol twice followed by tap and then distilled water.

\section{UNMASKING OF NUCLEIC ACIDS}

Sections were incubated in proteinase $K$ at a concentration of $500 \mu \mathrm{g} / \mathrm{ml}$ (about $20 \mathrm{units} / \mathrm{mg}$ protein) in PBS for 15 minutes at $37^{\circ} \mathrm{C}$. Slides were washed thoroughly in distilled water followed by PBS and dried at $75^{\circ} \mathrm{C}$.

\section{NISH}

Aliquots of hybridisation $\operatorname{mix}(9 \mu \mathrm{l})$ containing $10-20$ $\mathrm{ng}$ of the appropriate biotinylated or digoxigenin labelled probe together with $1 \mu \mathrm{g}$ sheared salmon sperm DNA as described ${ }^{7}$ were added to each well on multispot slides, covered with a glass coverslip (Chance, UK) and the slides placed in a moist Terasaki plate. Hybridisation mix consisted of $50 \%$ formamide, $5 \%$ dextran sulphate (BDH, UK), $2 \times \mathrm{SSC}$, and 0.05 mol/1 Tris-hydrochloric acid, $\mathrm{pH} 7.3 ; 1 \times \mathrm{SSC}=0.15$ $\mathrm{mol} / 1$ sodium chloride, $0.015 \mathrm{~mol} / 1$ sodium citrate. Sections and probes were simultaneously denatured at $95^{\circ} \mathrm{C}$ for 15 minutes on a solid stainless steel plate in a hot air oven and then hybridised at $42^{\circ} \mathrm{C}$ for two hours.

DETECTION OF HYBRIDISATION SIGNAL Slides were washed in three changes of $4 \times \mathrm{SSC}$ at $22^{\circ} \mathrm{C}$ (five minutes each change). They were then soaked in blocking agent TBT $(0.05 \mathrm{~mol} / 1$ Tris-hydrochloric acid, $0 \cdot 10 \mathrm{~mol} / 1$ sodium chloride $(\mathrm{pH} 7 \cdot 2)$ containing $3 \%$ bovine serum albumin, and $0.05 \%$ Triton $100(\mathrm{v} / \mathrm{v}))$ at $22^{\circ} \mathrm{C}$ for 10 minutes. Subsequent detection followed one of two procedures.

Digoxigenin probe detection: Slides were incubated for 30 minutes in alkaline-phosphatase conjugated antidigoxigenin (Boerhinger; West Germany) then washed in $0.05 \mathrm{~mol} /$ Tris hydrochloric acid, $0.1 \mathrm{~mol} / 1$ sodium chloride, $\mathrm{pH} 7.2$ (TBS) for five minutes twice. The signal was then developed using the alkaline phosphatase substrate, nitrobluetetrazolium (NBT) and 5bromo-4-chloro-3-indolyl-phosphate (BCIP): this was made up as previously described ${ }^{10}$ and stored in aliquots at $-20^{\circ} \mathrm{C}$ until required. Slides were incubated in the substrate at $22^{\circ} \mathrm{C}$ for $45-60$ minutes and the reaction stopped by washing in distilled water. Double probe detection: Sections were incubated at $22^{\circ} \mathrm{C}$ for 30 minutes with a mixture of streptavidinperoxidase conjugate (Dako: UK) diluted 1/100 in TBT and alkaline-phosphatase conjugated anti-digoxigenin (Boerhinger; West Germany), diluted 1/600 in TBT; in practice $1 \mu \mathrm{l}$ of antibody and $6 \mu \mathrm{l}$ of streptavidin was added to $600 \mu$ l of TBT. Unbound conjugate was removed by washing twice in TBS for five minutes and the sections incubated in the peroxidase substrate, 3-amino-9-ethylcarbazole (AEC): AEC ( $2 \mathrm{mg}$ ) was dissolved in $1.2 \mathrm{ml}$ dimethylsulphoxide in a glass tube and then added to $10 \mathrm{ml} 0.02 \mathrm{~mol} / \mathrm{l}$ acetate buffer, $\mathrm{pH} 5 \cdot 0-5 \cdot 2$. Hydrogen peroxide $(0 \cdot 8 \mu \mathrm{l}$ of $30 \%(\mathrm{v} / \mathrm{v}))$ was added and the final mix used immediately. Incubation was carried out at $22^{\circ} \mathrm{C}$ for 30 minutes and the reaction terminated by thorough washing in distilled water. After exposure to AEC slides were washed thoroughly in TBS followed by substrate buffer $(0.05 \mathrm{~mol} / 1$ Tris-hydrochloric acid, pH9.5, 0.1 mol $/ 1$ sodium chloride, $1 \mathrm{mmol} / 1$ magnesium chloride) before incubation in NBT-BCIP. The reaction was stopped by washing in distilled water for five minutes.

All slides, irrespective of the detection system, were air dried at $42^{\circ} \mathrm{C}$ and mounted in glycerol jelly.

\section{Results}

To detect two sequences simultaneously in the same cell entailed the use of two substrates with contrasting colours. The strategy adopted was to develop all digoxigenin labelled probes using the blue/black substrate NBT-BCIP as the anti-digoxigenin antibody is conjugated to alkaline phosphatase. Biotinylated probes were detected using streptavidin-peroxidase in conjunction with a red carbazole based substrate (fig 1). 


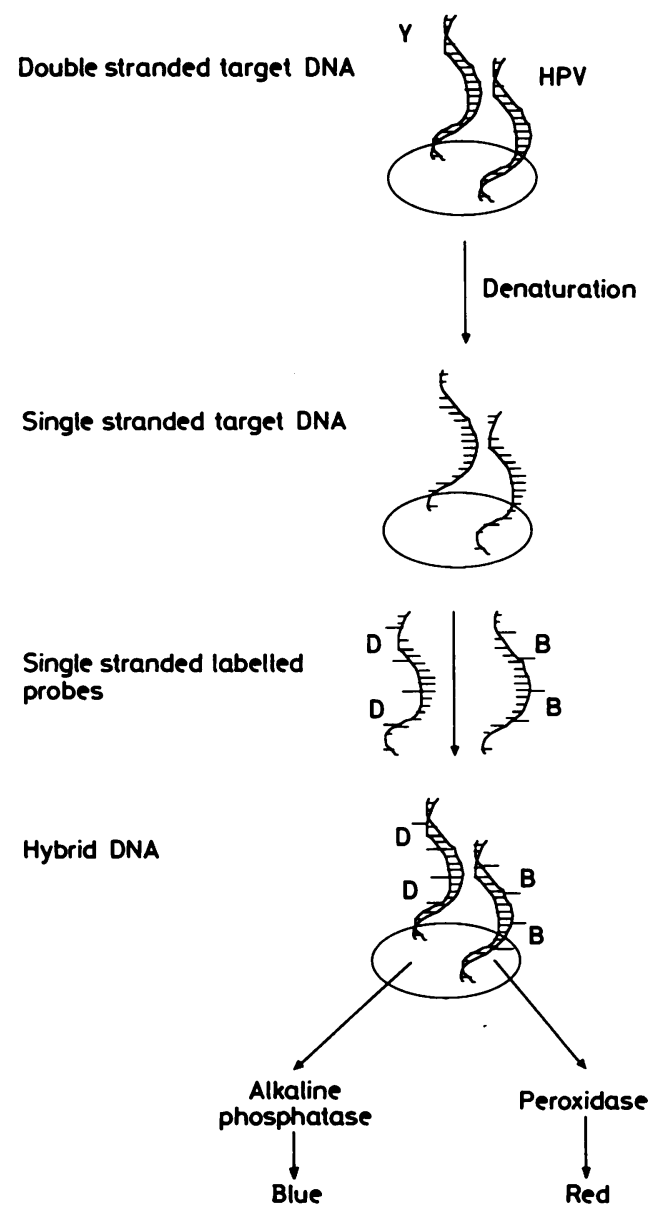

Fig 1 Schematic representation of detection system used for double labelling. $D=$ digoxigenin; $B=$ biotin.

Digoxigenin labelled pHY2.1 was used to detect the $Y$ chromosome in peripheral blood lymphocytes. This produced a clear signal with NBT-BCIP as substrate (fig 2). Using this method to label formalin fixed, paraffin wax embedded normal male human tonsil, the signal obtained using digoxigenin labelled pHY2.1 was comparable with that using biotin labelled probe (fig 3). Likewise, digoxigenin labelled HPV6 produced a strong signal in male condylomata acuminata (fig 4).

The best colour contrast was obtained using biotinylated HPV and digoxigenin labelled pHY2.1. This combination produced a diffuse red signal (corresponding to HPV) which was easily distinguishable from the discrete blue/black dot (representing the $Y$ chromosome) produced by NBT-BCIP (figs 5 and 6). If the probes were labelled the other way round-that is, biotinylated $\mathrm{pHY} 2 \cdot 1$ and digoxigenin labelled HPV - the diffuse blue/black signal of HPV masked the discrete red Y signal (data not shown). This can be controlled to some extent by limiting the enzyme reaction but the choice of colours to produce the best contrast for a given system is more appropriate.

\section{Discussion}

DNA probes labelled with digoxigenin by both chemical means ${ }^{11}$ and random priming ${ }^{12}$ have been used to detect DNA sequences on nitrocellulose filters. As shown here probes labelled with digoxigenin by nick translation, or random priming (Evans and McGee, unpublished observations), can be used as easily as biotin labelled probes to detect both mammalian and viral sequences in formalin fixed, paraffin wax embedded tissue. This reporter molecule therefore provides a useful alternative to biotin in NISH on paraffin wax sections and avoids the detection of endogenous biotin which is a problem in some tissues.

Having established that digoxigenin produces a signal comparable with biotin on paraffin wax sections, ${ }^{10}$ this paper goes on to show that both reporters can be used in the differential identification of two separate nucleic acid species in the same nucleus. When labelling two nucleic acid species, the particular combination of substrates selected depends on the type(s) of signal produced as any coloured substance (red or blue), when present as a dense dot, will tend to look dark. The system chosen here was detection of the Y chromosome and HPV6 in condylomata acuminata in men. These lesions are known to contain HPV6 or $11^{13}$ and the combination of the discrete $Y$ signal and diffuse HPV signal provide good morphological contrast. In general, it is also important that the two systems are of equivalent sensitivity to ensure that one signal does not dominate the other.

An advantage of the methodology described here and summarised in fig 1 is that biotin and digoxigenin labelled probes can be mixed together in the hybridisation cocktail and denatured and hybridised simultaneously with the target DNA, rather than adopting sequential hybridisation. The biotin labelled probe was detected using streptavidin conjugated to horseradish peroxidase with AEC as the substrate. This produces a red product and therefore the digoxigenin labelled probe was detected using alkaline phosphatase conjugated anti-digoxigenin, using NBT-BCIP, which generates a blue end product, as the substrate. Streptavidin and antibody conjugates can be mixed and applied simultaneously to the section, without cross reaction with each other or labelled probe. The incubation in substrates is performed sequentially as horseradish peroxidase and alkaline phosphatase have different pH optima. These two detection systems have been shown previously to be of equivalent sensitivity in NISH. ? 
Fig 2 Normal male human lymphocytes probed with digoxigenin labelled pHY2.1. Signal was developed using alkaline phosphatase-NBT-BCIP. A signal normally adjacent to the nuclear membrane is present in all cells.

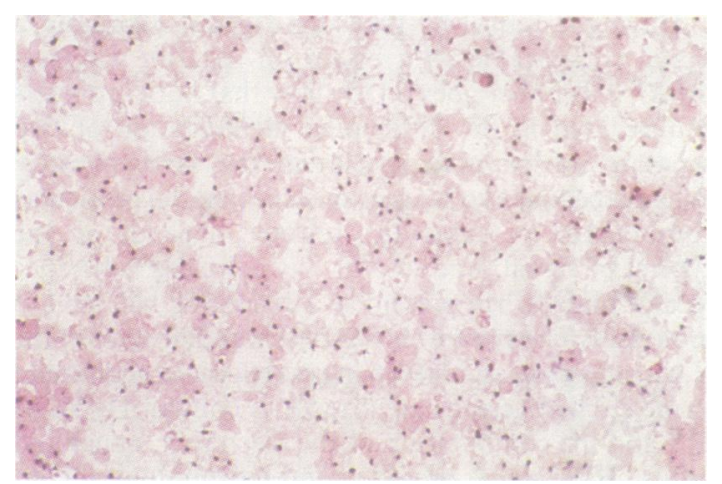

Fig $3 Y$ chromosome in formalin fixed, paraffin wax embedded normal male tonsil is shown by digoxigenin labelled pHY2 1. Signal was developed using alkaline phosphataseNBT-BCIP. A signal comparable with that using biotin labelled probes was obtained. Almost every cell in this $5 \mu \mathrm{m}$ section contains a Y chromosome.

Best results were obtained when the more diffuse signal of HPV was stained red using the biotin labelled probe and the discrete dots produced by the $Y$ chromosome blue/black using the digoxigenin labelled probe. When the red substrate was used to detect biotin labelled pHY2.1, the signal was less easily distinguished (although it was discernibly red) from the diffuse blue signal of digoxigenin labelled HPV. It is likely that the optimal colour contrast has to be determined by experiment for each system and depends primarily on the morphology of the signal to be detected. Using this method, signal from both probes was visualised within the same nucleus (figs $5 \mathrm{~b}$ and 6). Uninfected cells contain only the $Y$ chromosome but infected cells show two staining patterns. The nuclei contain either viral nucleic acid

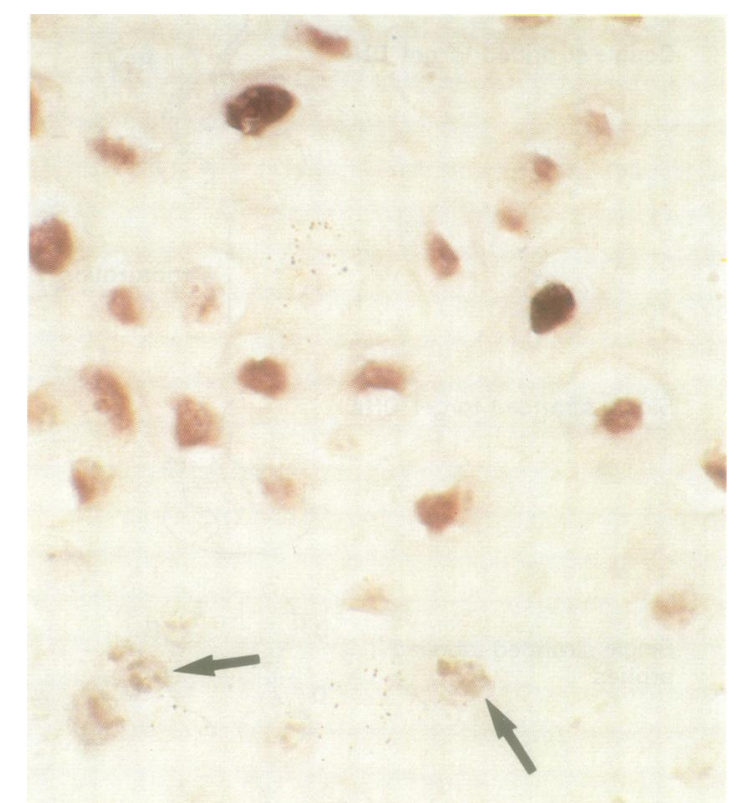

Fig 4 An anogenital condyloma acuminatum probed with digoxigenin labelled HPV6. Signal was developed as for pHY2.1. A clear nucleic acid signal can be seen in koilocytes and also in parabasal cells (arrows).

alone or the viral genome and the Y chromosome. The percentage of cells labelled with $\mathrm{pHY} 2 \cdot 1$, when lymphocytes or formalin fixed, paraffin wax embedded tonsil were probed, was $95-100 \%$ compared with 60 $70 \%$ in infected keratinocytes. This suggests either that some infected cells have lost the $\mathrm{Y}$ chromosome or that it is unavailable for hybridisation. This may be due to the nuclear changes which occur as keratinocytes mature and become anuclear on the skin surface.

The importance of this study lies not only in the demonstration of a $\mathrm{Y}$ chromosome inside a nucleus infected with HPV, but also in the fact that two nucleic acids can be labelled differentially within a single nucleus in archival material. This "model system" approach is a prelude to the application of double probing of archival sections for dual viral infections and numeration of chromosomal complement in tumour cells. It has been claimed by others using in situ hybridisation that anal and other warts are dually infected with HPV6 and $11 .^{14-16}$ We have recently shown that double HPV infection of the same cell with these subtypes does not occur in these lesions. ${ }^{17}$ Analysis of chromosome number by fluorescence NISH in tumour cells ${ }^{34}$ and in hereditary diseases, such as trisomy ${ }^{18}$ has received attention recently. The present technique can be applied to the identification 


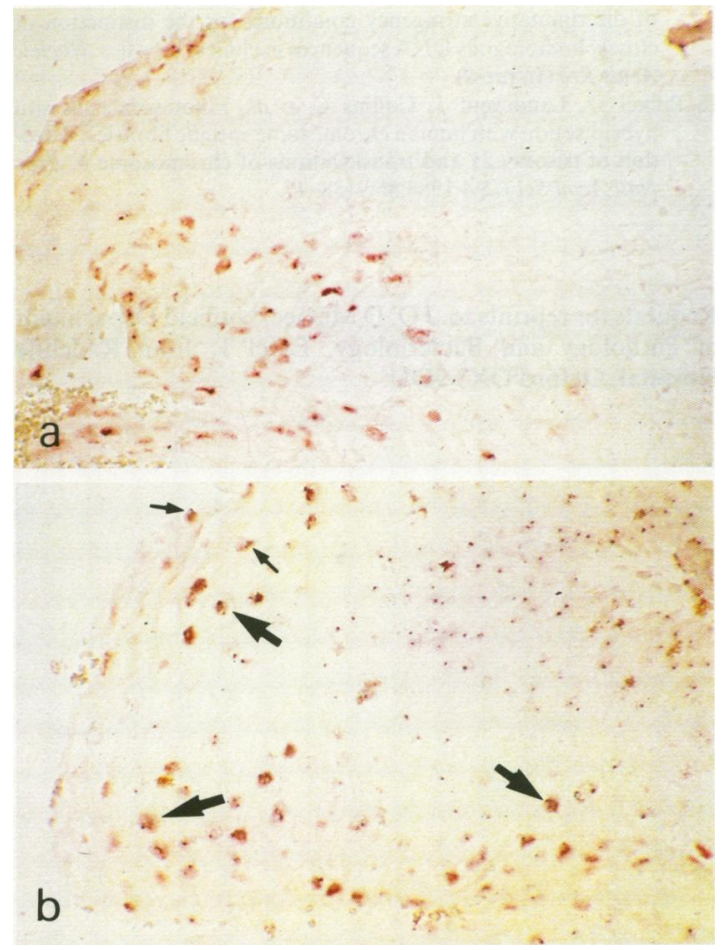

Fig 5 (a) A male anogenital condyloma probed with biotin labelled HPV6 and detected using peroxidase-AEC. Infecteu' koilocytes are red. Note that dense red dots are present in areas of heavy staining: these are discernibly red compared with the blue/black dots seen in figs $5 b$ and 6 .

(b) The same lesion probed with that of both biotin labelled HPV6 and digoxigenin labelled pHY2.1 and detected according to the scheme in Fig 1. Infected koilocytes give a red signal; the $Y$ chromosome can also be seen as a discrete blue black dot (large arrows). Note that not all of the surface keratinocytes contain a Y chromosome (small arrows).

of chromosome number using probes for repetitive DNA in archival material. Preliminary results in this laboratory indicate that not only can repeats be identified (Bhatt, Herrington, and McGee, unpublished observations) but that unique sequences such as $\beta$ globin can also be visualised in interphase cells by modification of the present method (Herrington and McGee, unpublished observations).

This method is easy, quick, and reliable. The whole procedure, from section cutting to probe visualisation, can be completed in about five hours. This is only 30 minutes longer than the detection of one nucleic acid.

CSH is a Cancer Research Campaign Clinical Research Fellow and Junior Research Fellow, Green College (University of Oxford). The work was supported by grants to J O'D McG from the CRC (UK).

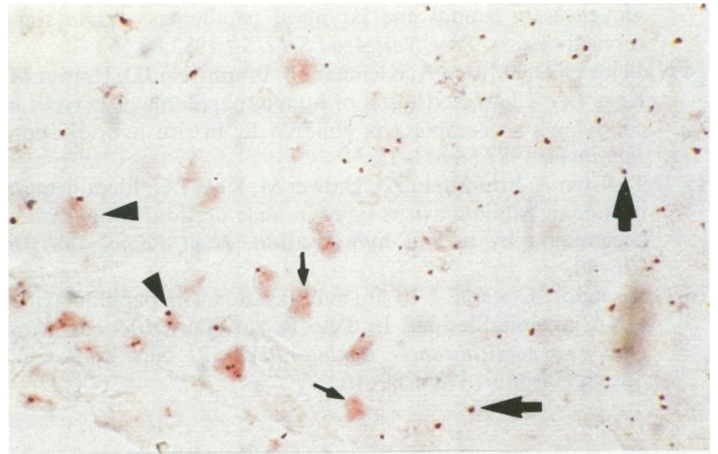

Fig 6 A high power view comparable with that of fig $5 b$. There are three types of staining pattern: cells containing the $Y$ chromosome but no virus (large arrows); cells containing only virus (small arrows); and cells containing both the $Y$ chromosome and HPV6 (arrowhead).

\section{References}

1 Wagner L, Worman CP. Colour-contrast staining of two different lymphocyte sub-populations: a two-colour modification of alkaline phosphatase monoclonal anti-alkaline phosphatase complex technique. Stain Technol 1988;63:129-35.

2 Wolber RA, Lloyd RV. Cytomegalovirus detection by nonisotopic in situ DNA hybridisation and viral antigen immunostaining using a two-colour technique. Hum Pathol 1988;19:736-41.

3 Hopman AHN, Ramaekers FCS, Raap AK, et al. In situ hybridisation as a tool to study numerical chromosome aberrations in solid bladder tumours. Histochemistry 1988;89:307-16.

4 Cremer T, Tesin D, Hopman AHN, Manuelidis L. Rapid interphase and metaphase assessment of specific cromosomal changes in neuroectodermal tumour cells by in situ hybridisation with chemically modified DNA probes. Exp Cell Res 1988;176:199-220.

5 Trask B, Van Den Engh G, Pinkel D, et al. Fluorescence in situ hybridisation to interphase cell nuclei in suspension allows flow cytometric analysis of chromosome content and microscopic analysis of nuclear organisation. Hum Genet 1988;78:251-9.

6 Devilee P, Thierry RF, Kievits T, et al. Detection of chromosome aneuploidy in interphase nuclei from human primary breast tumours using chromosome-specific repetitive DNA probes. Cancer Res 1988;48:5825-30.

7 Herrington CS, Burns J, Graham AK, Evans MF, McGee JO'D. Interphase cytogenetics using biotin and digoxigenin-labelled probes 1: relative sensitivity of both reporter molecules for HPV16 detection in CASki cells. J Clin Pathol 1989;41:592-600.

8 Cooke HJ, Schmidtke T, Gosden JR. Characterisation of a Human $\mathrm{Y}$ chromosome repeated sequence and related sequences in higher primates. Chromosoma 1982;87:491-502.

9 De Villiers E-M, Gissman L, Zur Hausen H. Molecular cloning of viral DNA from human genital Warts. J Virol 1981;40:932-5.

10 Burns J, Graham AK, McGee JO'D. Non-isotopic detection of in situ nucleic acid in cervix: an updated protocol. J Clin Pathol 1988;41:897-9.

11 Schafer R, Zischler H, Epplen JT. DNA fingerprinting using nonradioactive oligonucleotide probes specific for simple repeats. Nucleic Acids Res 1988;16:9344.

12 Dooley S, Radtke J, Blin N, Unteregger G. Rapid detection of DNA-binding factors using protein-blotting and digoxigenindUTP marked probes. Nucleic Acids Res 1988;16:11839.

13 Gissman L, Wolnik L, Ikenberg H, Koldovsky U, Schnurch HG, 
Zur Hausen H. Human papillomavirus types 6 and 11 DNA sequences in genital and laryngeal papillomas and in some cervical smears. Proc Natl Acad Sci USA 1983;80:560-3.

14 Vallejos H, Del Mistro A, Kleinhaus S, Braunstein JD, Halwer M, Koss LG. Characterisation of human papillomavirus types in condylomata acuminata in children by in situ hybridisation. Lab Invest 1987;56:611-15.

15 Del Mistro A, Braunstein JD, Halwer M, Koss LG. Identification of human papillomavirus types in male urethral condylomata accuminata by in situ hybridisation. Hum Pathol 1987;18: 936-40.

16 Grussendorf-Conen E-I. In situ hybridisation with papillomavirus DNA in genital lesions. In: Peto R, zur Hausen H, eds. Viral etiology of cervical cancer, Banbury Report 21. New York: Cold Spring Harbour, 1986:239-46.
17 Herrington CS, Burns J, Graham AK, McGee JO'D. Evaluation of discriminative stringency conditions for the distinction of closely homologous DNA sequences in clinical biopsies. Nucleic Acids Res (In press).

18 Pinkel D, Landegent J, Collins C et al. Fluorescence in situ hybridisation with human chromosome specific libraries: detection of trisomy 21 and translocations of chromosome 4. Proc Natl Acad Sci USA 1988;85:9138-47.

Requests for reprints to: J O' D McGee, Nuffield Department of Pathology and Bacteriology, Level 1, John Radcliffe Hospital, Oxford OX3 9DU. 